\title{
Upscaling of a local model into a larger-scale model
}

\author{
Luc Vandenbulcke ${ }^{1,2}$ and Alexander Barth ${ }^{3}$ \\ ${ }^{1}$ seamod.ro, Jailoo srl, Salatrucu, Romania \\ ${ }^{2}$ MAST, Université de Liège, Liège, Belgium \\ ${ }^{3}$ GHER, Université de Liège, Liège, Belgium
}

Correspondence: Luc Vandenbulcke (luc@seamod.ro)

Received: 8 July 2018 - Discussion started: 19 July 2018

Revised: 5 February 2019 - Accepted: 4 March 2019 - Published: 22 March 2019

\begin{abstract}
Traditionally, in order for lower-resolution, globalor basin-scale (regional) models to benefit from some of the improvements available in higher-resolution subregional or coastal models, two-way nesting has to be used. This implies that the parent and child models have to be run together and there is an online exchange of information between both models. This approach is often impossible in operational systems where different model codes are run by different institutions, often in different countries. Therefore, in practice, these systems use one-way nesting with data transfer only from the parent model to the child models. In this article, it is examined whether it is possible to replace the missing feedback (coming from the child model) by data assimilation, avoiding the need to run the models simultaneously. Selected variables from the high-resolution simulation will be used as pseudo-observations and assimilated into the lowresolution models. This method will be called "upscaling".

A realistic test case is set up with a model covering the Mediterranean Sea, and a nested model covering its northwestern basin. Under the hypothesis that the nested model has better prediction skills than the parent model, the upscaling method is implemented. Two simulations of the parent model are then compared: the case of one-way nesting (or a stand-alone model) and a simulation using the upscaling technique on the temperature and salinity variables. It is shown that the representation of some processes, such as the Rhône River plume, is strongly improved in the upscaled model compared to the stand-alone model.
\end{abstract}

\section{Introduction}

In the present-day operational oceanography landscape, services are provided at different scales by different expert centres. At the European Union level, the Copernicus Marine Environment Monitoring Service (CMEMS) provides reanalyses, analyses and forecasts at global and basin scales. The models for the different basins are run by different institutes and centres within the regional monitoring and forecasting centres. Various oceanographic centres then use the CMEMS products to provide initial and/or boundary conditions to their respective models. These subregional and coastal models benefit from the specific knowledge of the local teams in their particular area of interest. Furthermore, nested models usually run at higher resolution and may include more accurate data (bathymetry, river discharge data, etc.) and processes of smaller scales that cannot be easily included in basin-scale models. High-resolution observations such as satellite sea surface temperature (SST) and recent ultra-high-resolution products (see, e.g., Le Traon et al., 2015) have been shown to be best assimilated into nested models as chances are higher that the observed processes are well represented (Vandenbulcke et al., 2006). Similarly, highresolution observations of currents by high-frequency radars are expected to benefit models with a similar high resolution (i.e. nested models) most.

When parent and child models are run together (meaning, concurrently and on the same computing platform), it is possible to use two-way nesting; the benefits mentioned above of using a nested model are then transferred back to the basinscale model. This has been shown numerous times in the literature, (e.g. Barth et al., 2005; Debreu et al., 2012). The beneficial impact of the feedback from nested to the parent 
model is visible even outside the domain of the nested model. This constitutes the baseline hypothesis of the present study: it is desirable to "copy" the results of the nested model into the parent model.

To emulate this nesting feedback, missing in the operational context, it is analysed whether results from the subregional model can be used as pseudo-observations and assimilated into the basin-scale model. Indeed, data assimilation is not limited to the use of (real) observations by measurement devices. Onken et al. (2005) used data assimilation as a substitute for one-way nesting in a cascade of nested models. Alvarez et al. (2000) used a statistical model to predict SST, which was then assimilated as pseudo-observations in a hydrodynamic model (Barth et al., 2006). In the proposed "upscaling" method, the pseudo-observations come from the nested model. From the point of view of the forecasting centres, a data assimilation scheme is already implemented in the basin-scale model. Hence, implementing the upscaling method only requires obtaining the high-resolution data and assimilating (parts of) it, along with the real observations, during the analysis phase of the system.

When using grid nesting, problems at the open boundary of the child model include stratification mismatches, artificial waves, artificial rim currents, and ultimately instabilities and model blow-up (Mason et al., 2010; Debreu et al., 2012). By upscaling the child model into the parent model, the latter will progressively gain consistency with the child model solution within its domain, being beneficial for the child model over time. Upscaling can potentially reduce the risk of discrepancies at the open-sea boundary.

Upscaling can also be seen as using a high-resolution model as a "measurement device" that replaces ever too sparse (real) measurements. Guinehut et al. (2002, 2004) showed that a coverage of the North Atlantic with a $3^{\circ}$ resolution grid of Argo floats allows effectively representing the large scales. Using a $5^{\circ}$ array reduces the precision of the estimated fields by half. Currently, some CMEMS areas are largely undersampled.

Upscaling can be understood as a complement to downscaling (initialization) techniques such as the Variational Initialization and Forcing Platform (VIFOP) tool presented in Auclair et al. (2000, 2001) or in Simoncelli et al. (2011). The point of these methods is to combine interpolated fields coming from the large-scale model (the background or first-guess field) and existing high-resolution fields, so that small-scale structures present in coastal models are not lost whenever the high-resolution model is (re)-initialized by fields interpolated from the basin-scale model, and the obtained fields are physically balanced with respect to the coastal physics. If upscaling is used to improve the basin-scale fields and make them agree with them with the coastal model, the "first guess" will be already much better.

Schulz-Stellenfleth and Stanev (2016) represent another recent example showing the benefits of two-way nesting, especially in sophisticated modern-day forecasting systems.
The study demonstrates that two-way nesting is critical for correct energy transfers between large and small scales (especially in coupled ocean-wave-atmosphere models) for cross-border advection, for the correct use of high-resolution coastal observations that cannot be fed directly into a largescale model, etc. Acknowledging that operational systems only use one-way nesting, Schulz-Stellenfleth and Stanev (2016) therefore strongly advocate research into upscaling techniques. The present article tries to develop precisely such a technique.

In this article, the upscaling procedure is tried out in a realistic, nested-model configuration covering the Mediterranean Sea and the north-western basin and simulating the year 2014. The same model, NEMO 3.6 (Madec, 2008), and the same vertical resolution, are used for both configurations (only the horizontal grid is different). It is not expected that the conclusions of the study would be fundamentally different if different models and vertical grids are used for parent and child models. If different model codes were used, they could represent different processes. Hence, this should be taken into account by modifying the (representativity part of the) observation error covariance matrix when performing the data assimilation of the pseudo-observations. Examples of such contributions to the representativity error could be

- different vertical coordinates (see above);

- different implementations of the ocean surface: rigid lid or free surface; for the latter, linear or non-linear representation;

- hydrostatic model or not;

- different atmospheric forcing fields;

- different turbulent closure schemes;

- different numerical schemes for advection, horizontal diffusion, etc.

The most striking difference between the parent and child models however, remains the horizontal resolution, and therefore, the general conclusions of the paper are expected to be valid, and upscaling should not be limited to the case of parent and child models being identical.

In this study, it is not the aim to verify that the nested model is indeed more realistic, according to some metrics than the parent model. Rather, this constitutes the baseline hypothesis, and thus it is always considered beneficial to bring the parent model simulation closer to the child model simulation. It should be noted that some high-resolution processes, resolved by the nested model but not by the parent model, could have large phase errors in the nested model. In this case, the baseline hypothesis would be violated, and the nested model could actually have higher errors than the former. This aspect is not considered in the paper.

The parent model (also called "low-resolution" model) and the child (or "nested" or "high-resolution") model and 
the data assimilation scheme are described in Sect. 2. The parent model will be run both in "free" mode, and "upscaled" mode (i.e. assimilating pseudo-observations from the child model). The "free model" is equivalent to a stand-alone model; i.e. even if there are nested models, it is not influenced by them. Section 3 proposes some metrics to evaluate the system, related to the Rhône River plume, the cross-shelf exchanges, the large-scale current, SST and the formation of Western Mediterranean Deep Water. Results are given in Sect. 4 and a conclusion is presented in Sect. 5 .

\section{Model and data assimilation configuration}

\subsection{Hydrodynamic model}

The upscaling technique has been implemented in the northwestern Mediterranean Sea (NW-Med), including the Gulf of Lion (GoL) and the Ligurian Sea (see Fig. 2). The region is characterized by large-scale currents (the Northern Current also called Liguro-Provençal Current, created by the junction of the Eastern and Western Corsican currents; see, e.g., Pinardi et al., 2015), by intense meso-scale activity and by inertial oscillations. Furthermore, the NW-Med is the siege of formation of Western Mediterranean Deep Water (WMDW), important to the circulation in the whole Mediterranean Sea (e.g. Millot, 1999; Pinardi et al., 2015; Bosse et al., 2015; Somot et al., 2018; Simoncelli et al., 2018).

A realistic, one-way nested configuration was implemented using the NEMO 3.6 model and the AGRIF nesting tool (Debreu et al., 2008), covering respectively the Mediterranean Sea (MED) with a $8 \mathrm{~km}$ horizontal resolution and the north-western Mediterranean basin (NW-Med). The parent model resolution is similar to the previous version of the CMEMS Mediterranean Sea analysis- forecasting system (up to October 2017) (Clementi et al., 2017) and to the present reanalysis $\left(1 / 16^{\circ}\right)$ (Simoncelli et al., 2014). The child model horizontal resolution is $1.6 \mathrm{~km}$.

When implementing the upscaling method, it is expected that after some time, the feedback from the NW-Med model will modify the Northern Current position and intensity in the parent model, which will in turn influence the NW-Med model through its open-sea boundary. The boundary condition provided by the MED model also influences the stratification of the water column, which is important for the preconditioning of the convection (Samuel Somot, personal communication, 2018).

Both model bathymetries are interpolated from the GEBCO (GEneral Bathymetric Chart of the Oceans) bathymetry. Thanks to its higher resolution, the bathymetry of the nested model $\left(1 / 80^{\circ}\right)$ is more realistic than in the parent model, at the coastline and, more importantly, in the different canyons on the Gulf of Lion shelf break. The temperature and salinity initial condition is interpolated from the CMEMS Mediterranean reanalysis $\left(1 / 16^{\circ}\right)$ for 1 January 2014 (see https://doi.org/10.25423/medsea_reanalysis_ phys_006_004, last access: 20 December 2018), using trilinear interpolation and linear extrapolation where needed. The model starts from rest. Atmospheric fluxes are computed using the bulk formula from the NEMO Mediterranean Forecasting System (MFS) module; the atmospheric forcing fields are obtained from ECMWF ERA Interim with a temporal resolution of $3 \mathrm{~h}$ and a horizontal resolution of $0.75^{\circ}$ re-interpolated by the ECMWF server to $0.125^{\circ}$ (Dee et al., 2011). In the MED model, the flow between the Black Sea and the Mediterranean Sea, through the Marmara Sea and the Dardanelles Strait, is modelled as a river, using climatological flow, temperature and salinity values. The salinity of the incoming water has a minimum and maximum of 22.5 and 27.5 psu reached in July and March respectively. Five other rivers (Rhône, Po, Ebro, Nile, Drin) are also represented, and monthly climatologic values for the flow and temperature are used, whereas the salinity is put to $5 \mathrm{psu}$, except for the Drin river where is it put at 2 psu. Using climatologic monthly values is coherent with the operational set-up in the CMEMS Mediterranean system, although the latter represents many more small rivers.

Daily Rhône River discharge measurements at the Beaucaire station were obtained from the Compagnie du Rhône, in order to be used in the nested NW-Med model. Interestingly, the total annual flow computed from the climatology and from the measured values for 2014-2015 is very similar ( $1 \%$ difference). However seasonal and daily values can be very different (see Fig. 1a). In particular, during the considered period, the climatology underestimates the winter discharge but overestimates the summer discharge. Hence, depending on the dataset used, it is expected that the modelled river plume will also be significantly different. This is illustrated in Fig. 1b, showing the surface salinity difference using climatological or daily discharge data in the child model (NW-Med) after 1 month of spin-up. The plume obtained using real river discharge extends much further offshore, almost completely across the Gulf of Lion, whereas the plume obtained with the climatological river discharge essentially stays at the coast close to the river mouth. This is consistent with the much larger (almost double) discharge values observed in the real river data during January 2014.

\subsection{Upscaling experiment description, ensemble generation and data assimilation scheme}

In order to assimilate pseudo-observations into the basinscale models, different set-ups could be implemented, regarding the choice of the pseudo-observations, the frequency of assimilation, the data assimilation scheme itself, etc. The choices described below are consistent with current-day practices in the CMEMS operational systems. In particular, none of them currently assimilates velocity fields, and all of them use parameterized model state vector error covariances. 

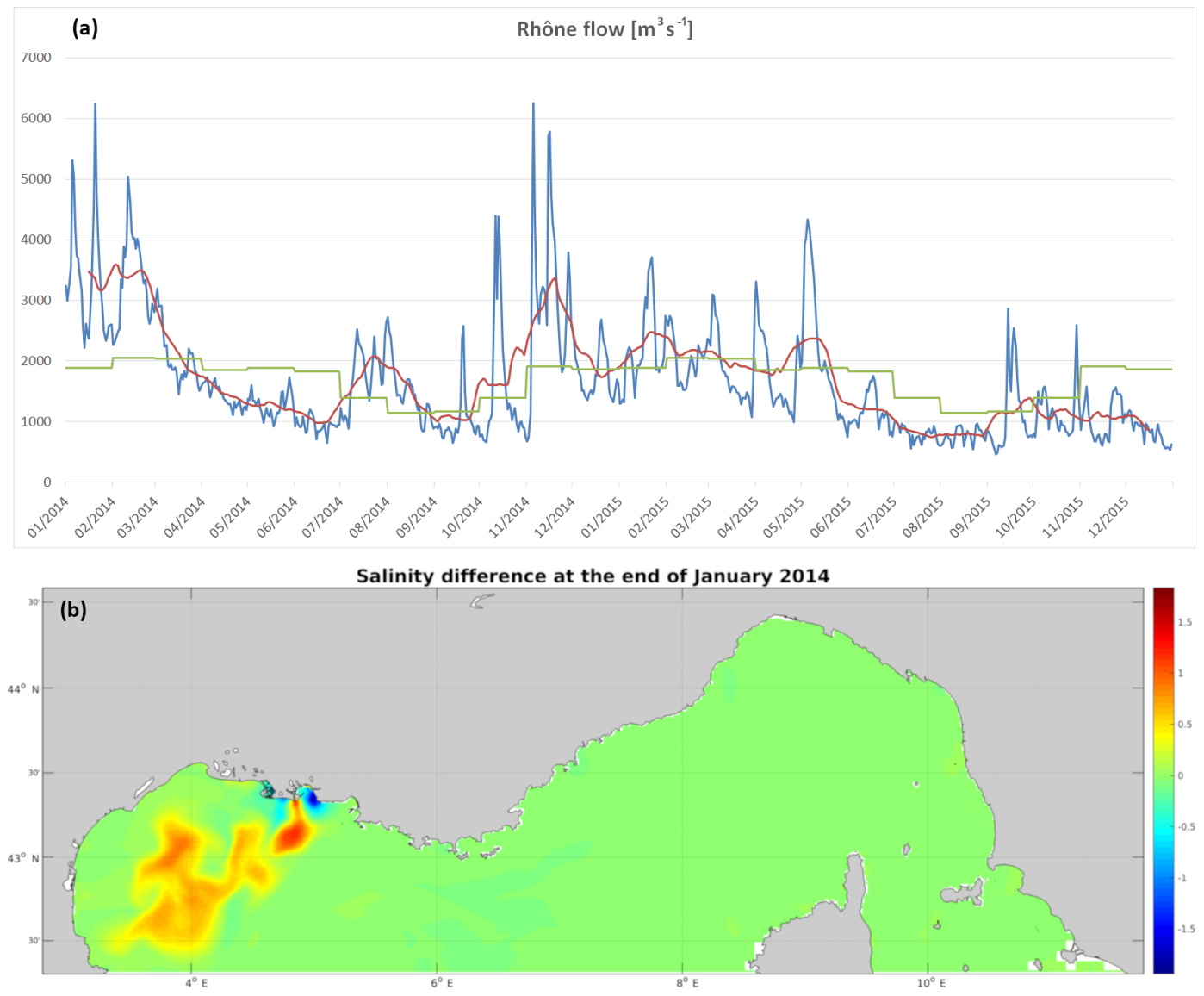

Figure 1. (a) Rhône River discharge from (green) the climatology, (blue) the measurements by the Compagnie du Rhône at the Beaucaire station and (red) the 1-month moving average of the measurements. (b) Difference of surface salinity in two different model runs of the nested grid on 28 January 2014, when using climatological or measured Rhône discharge values (i.e. using the green or blue curve in a).

Only one system (the Arctic system) currently uses an ensemble Kalman filter, but the other systems are planning to evolve toward ensemble simulations in the future.

The following settings were chosen for the current experiment. The filter will be an ensemble Kalman filter (the parent model is thus transformed into an ensemble of models). Assimilation will be performed daily. Only temperature and salinity will be used as pseudo-observations; the thinned 3D fields will be used. Velocity and surface elevation are not updated by the data assimilation procedure. Thinning is realized by taking the average of five by five cells of the nested model. The thinned pseudo-observations coming from the nested model are then considered independent; i.e. their error covariance matrix is diagonal. This is still a strong assumption which should be taken into account when determining the (diagonal) part of the observation error covariance matrix.

The members of the ensemble have perturbed initial conditions, atmospheric forcing fields and Rhône River discharge, similar to Auclair et al. (2003). The initial condition is the randomly weighted sum of the real initial condition (1 Jan- uary 2014) and six other initial conditions (1 year, 20 days and 10 days earlier, and 10 days, 20 days and 1 year later). The weight of the real initial condition is a random normal number chosen in the Gaussian distribution with mean 0.5 and standard deviation 0.2 ; if necessary, the random number is then limited back into [0.2 0.8], whereas the six remaining weights are random numbers chosen uniformly in [0 1], and normalized so that the sum of all seven weights is 1 . This procedure ensures that the stability of each member is not modified (for example, the linear combination of seven stable water columns is still a stable water column).

The atmospheric forcing fields of air temperature at $2 \mathrm{~m}$ height and wind speed at $10 \mathrm{~m}$ height are perturbed following the same procedure as in Barth et al. (2011) and Vandenbulcke et al. (2017). Point-wise, the forcing fields are decomposed in Fourier series (from $3 \mathrm{~h}$ to 1 year). For each member, a random field is generated, using these Fourier modes and random coefficients which have a temporal correlation length corresponding to the respective mode. This random field is added to the original field. 


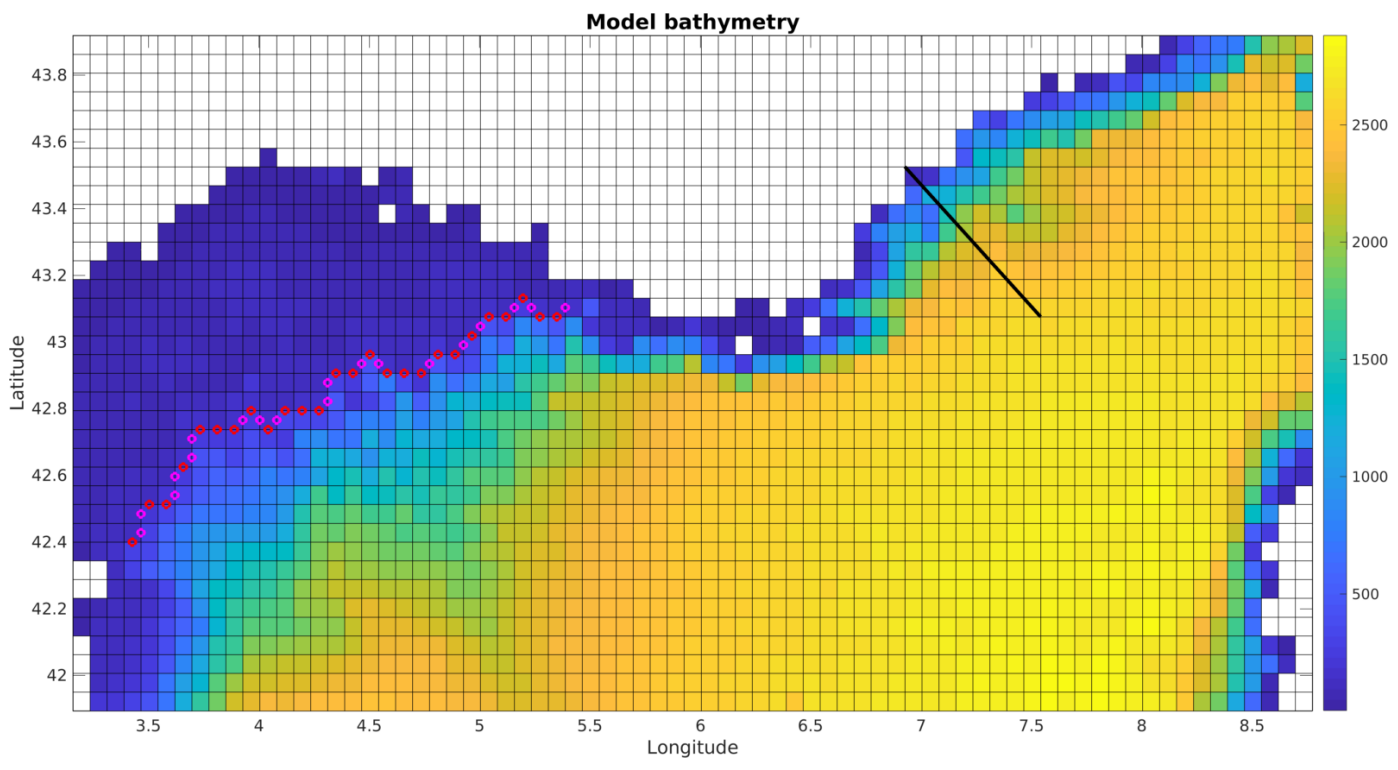

Figure 2. Zoom of the MED model grid, with the positions for computing the Northern Current metric (black line) and the cross-shelf transport metric (magenta and red dots).

The Rhône River discharge is perturbed using a random walk approach, with the expected perturbation after 1 year set to $20 \%$. The other rivers are outside the observed part of the domain, and their discharge is not perturbed. With all three perturbations, an ensemble of 100 members is then spun-up for 1 month.

Data assimilation is performed by the Ocean Assimilation Kit (OAK) package (Barth et al., 2008) implementing different filters such as SEEK and the ensemble Kalman filter (EnKF). Different variants of the EnKF exist, and are classified in stochastic and deterministic methods. The former require the perturbation of the observations, adding sampling noise. The latter, also called ensemble square root filters, do not present this requirement; the perturbation approach is only applied in the model to obtain model errors. Different variants are compared in Tippett et al. (2003). One variant, called the ensemble transform Kalman filter (Bishop et al., 2001; Wang et al., 2004), is used in this study. The filter equations are listed in Barth and Vandenbulcke (2017).

Nerger et al. (2012) summarizes how the spurious longrange correlations can be suppressed using so-called covariance localization or domain localization and its additional observation localization. OAK uses the latter variant introduced in Hunt et al. (2007). In essence, the state vector is split into subdomains (water columns). In every water column, the analysis is performed independently (domain localization). In addition, for every water column, only nearby observations are used and the inverse of their error variance is multiplied by a localization function (observation localization). In the current set-up, the localization function is a radial Gaussian function with an $e$-folding distance of $30 \mathrm{~km}$.
The observation errors for temperature and salinity are set respectively at $0.3^{\circ} \mathrm{C}$ and $0.09 \mathrm{psu}$. These values were determined after a sensitivity experiment with observation errors of $0.5^{\circ} \mathrm{C}, 0.15 \mathrm{psu} ; 0.3^{\circ}, 0.09 \mathrm{psu} ; 0.2^{\circ} \mathrm{C}, 0.05 \mathrm{psu}$; and $0.1^{\circ} \mathrm{C}, 0.03 \mathrm{psu}$ as a trade-off between generating a close emulation of two-way nesting (hence very small observation errors) and generating fields that are as balanced as possible and that will not cause adjustment shocks in the model (hence larger observation errors). With the latter two choices for the observation error, the obtained assimilation increment was not much larger than with the final choice of $0.3^{\circ}, 0.09 \mathrm{psu}$, but qualitatively, unrealistic small-scale variations started to appear.

From a technical point of view, OAK allows using a multivariate, multi-grid state vector. As the Mediterranean model is parallelized in 64 tiles, the multi-grid feature allows updating the tiles directly from the Mediterranean model restart files, influenced by the nested model, without including the other tiles in the state vector. The procedure thus allows skipping the reconstruction of the complete Mediterranean restart files. It should be noted that the tiles of the parent model, considered in the data assimilation procedure, are the ones covering the nested-model area but also the neighbouring ones which are influenced by the data assimilation.

\section{Metrics}

To assess the upscaling method, five metrics were defined, that allow a comparison of the nested model and the parent model, in both cases without upscaling (MED free model) and with upscaling (MED upscaled model). If upscaling is 
successful, the parent model with upscaling will be closer to its nested model than its counterpart without upscaling.

\subsection{Cross-shelf transport}

The penetration of offshore water on the GoL (or inversely when negative transport values are obtained) is critical for the circulation on the shelf, for the shelf-open-sea exchanges, etc. It is obtained by integrating the current over the boundary shown in Fig. 2. This metric is useful to compare basin-scale models (free and upscaled) and check whether the upscaling procedure is able to drive the solution toward the nestedmodel solution. The intensity of the cross-shelf transport cannot, however, be compared to real measurements (due to a lack of them).

\subsection{Northern Current intensity}

The Northern Current (NC) is the most important large-scale feature in the region of interest. It is considered to have a width of $40-50 \mathrm{~km}$ during summer and $20-30 \mathrm{~km}$ during winter, but the most offshore currents do not modify the transport much. Similarly, the NC is considered to be $100-$ $200 \mathrm{~m}$ deep in summer and $250-400 \mathrm{~m}$ in winter. Following Alberola et al. (1995), its intensity is obtained by integrating the currents normal to a line from Nice to the location at $43.0756^{\circ} \mathrm{N}, 7.5415^{\circ} \mathrm{E}, 214 \mathrm{~km}$ to the south-east, indicated in Fig. 2. As for the previous metric, this metric only allows inter-comparing different models.

\subsection{Rhône River plume}

The plume of the Rhône River is measured by selecting all points around the river mouth with a salinity smaller than 37 psu and then choosing the most distant one from the river mouth. This provides the plume length and direction, although it may be an approximation: the plume can be curved, in which case its real length is greater than the estimation, or it can cover a large area, in which case the algorithm still obtains an azimuth although in reality it is not well-defined.

This metric can be used quantitatively to compare models. Furthermore, it can be used to compare model results to real measurements. Indeed, although the real Rhône River plume length and direction are not measured directly, they can be estimated from satellite chlorophyll $a$ images. The modelobservations comparison is then qualitative.

\subsection{Sea surface temperature}

This metric is the root mean square (rms) difference between the parent model and the observed SST. For the latter, the level-3 (L3) images are used.

\subsection{Western Mediterranean Deep Water formation}

Following Bosse et al. (2015) and references herein, the formation zone of WMDW is located at $41-43^{\circ} \mathrm{N}, 4-6^{\circ} \mathrm{E}$.
WMDW forms an easily identifiable water mass: it has a temperature between 12.86 and $12.89^{\circ} \mathrm{C}$, a salinity of $38.48-$ $38.50 \mathrm{psu}$, and its depth is greater than $1000 \mathrm{~m}$. The nestedmodel (NW-Med) southern boundary is at $42.3^{\circ} \mathrm{N}$, and hence only a part of the formation area is included in the area of MED covered by pseudo-observations. The WMDW metric measures the total volume $\left(\mathrm{m}^{3}\right)$ of WMDW in the domain covered by the NW-Med model and is used to compare the different models.

\section{Results}

The temperature difference between the (unperturbed) parent and child models at the end of the spinup (31 January 2014) is represented in Fig. 3 on the child model grid. There are large temperature differences at the shelf break of the Gulf of Lion (the canyons are much better represented in the nested model), which extend all the way from the surface to the bottom of the Gulf of Lion. Other large differences appear in the Eastern and Western Corsican currents and their junction resulting in the Northern Current as well as at the southern open boundary. The difference in salinity (not shown) has large values around the Rhône River plume (over 1 psu) and to a lesser extent in the Eastern Corsican Current. It appears that after a month, the differences are already significant, and if one trusts the nested model more, then it would be beneficial to bring these differences back to the basin-scale model.

At the end of the spin-up, the spread of the ensemble of models (Fig. 4) is very visible over the basin at all river mouths but also in other areas (Alboran Sea, Tunesian coastal zone, etc.) as all three perturbations are applied at once. The ensemble spread is also visible in depth (i.e. deeper than when only the river discharge is modified).

As an example, the first data assimilation cycle is shown in Fig. 5 depicting SST. The L4 SST image is shown only for visual comparison. Qualitatively, it appears that upscaling changes important features: the Rhône River plume is oriented offshore instead of being mostly along-shore, fronts seem to be better defined, and the Northern Current flows along the shelf break instead of covering a large part of the shelf. The nested model and the upscaled model seem to be in closer agreement with the satellite image than the free model.

\subsection{Cross-shelf transport}

The flow across the shelf break is represented in Fig. 6 for the basin-scale model in the free and upscaled cases. Although alternating periods of inflow and outflow appear, the transport seems to show a chaotic behaviour. Yet it can be seen that while both models are generally similar, some periods exist where the simulated transport is very different. During the first month (February 2014), the free model predicts a net outflow during the first 2 weeks, followed by a net inflow during the last 2 weeks. The nested model (not shown) 


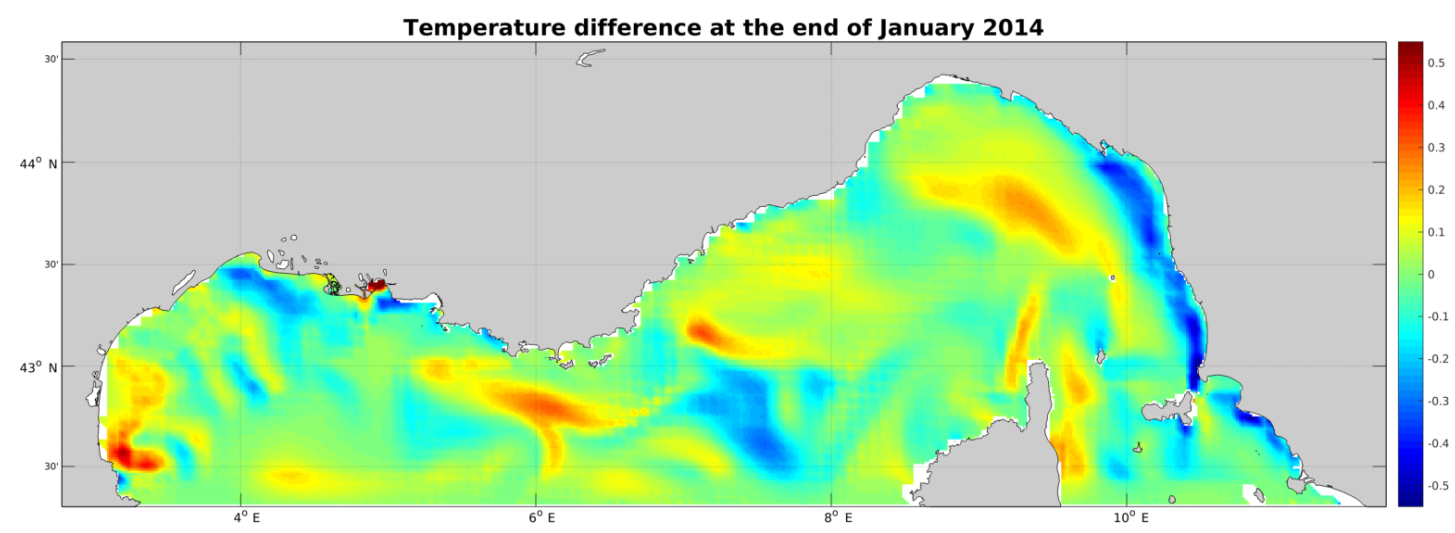

Figure 3. Temperature difference between the parent and nested models on 31 January 2014, projected on the nested-model grid.
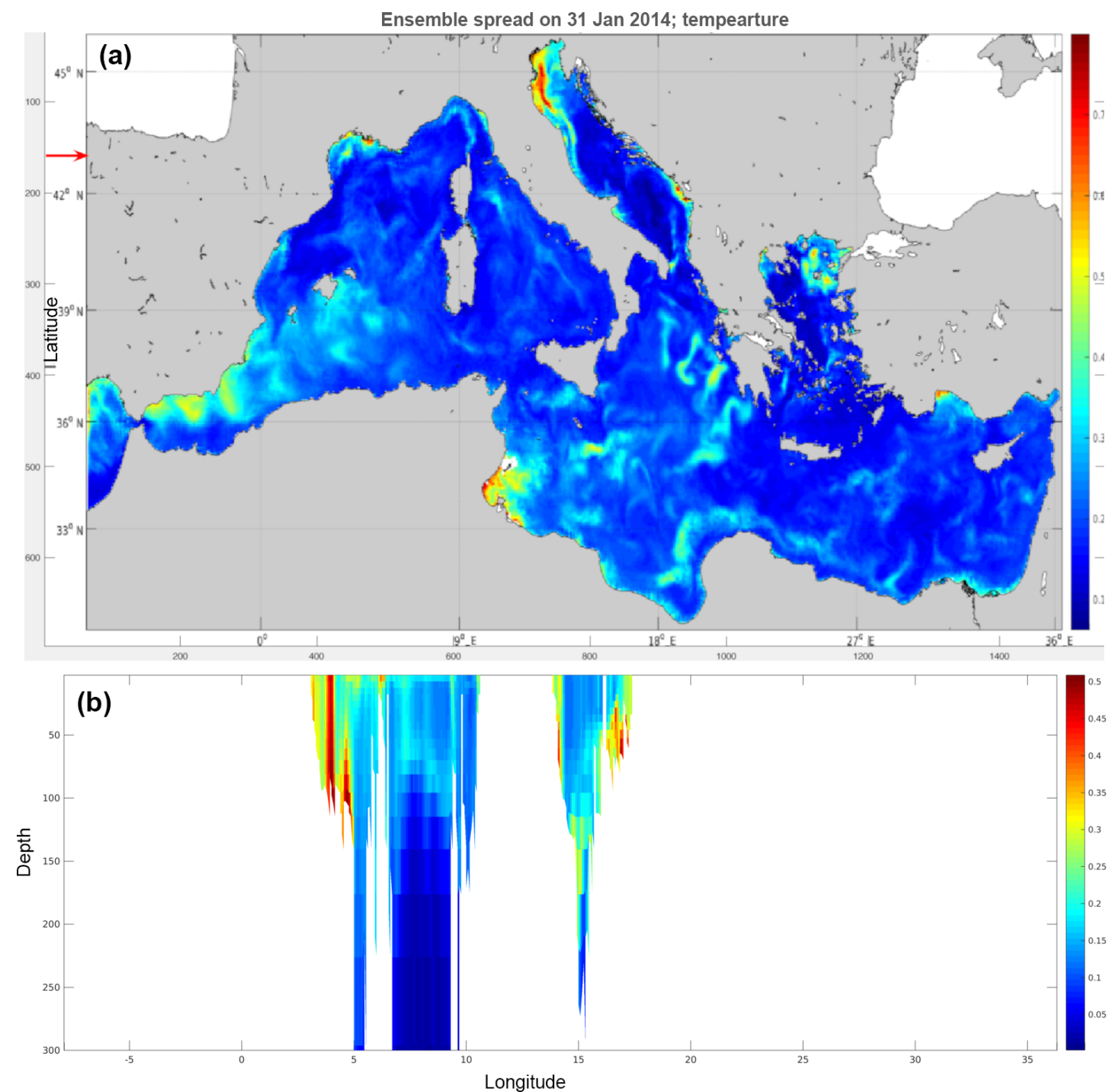

Figure 4. Spread of the ensemble of MED models on 31 January 2014: (a) surface temperature; (b) section at $43^{\circ} \mathrm{N}$, indicated by a red arrow in (a). 
MED free model (projected on NW-Med grid)

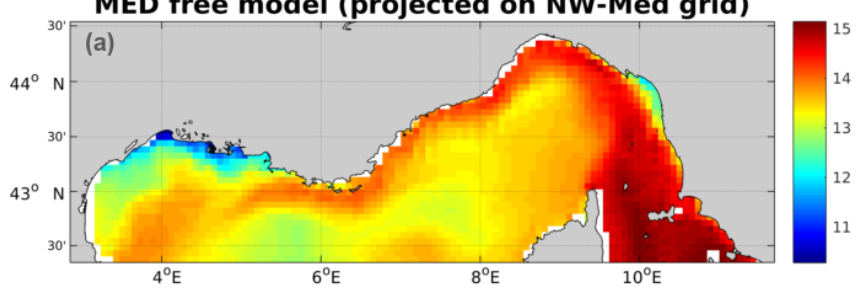

MED upscaled model (projected on NW-Med grid)

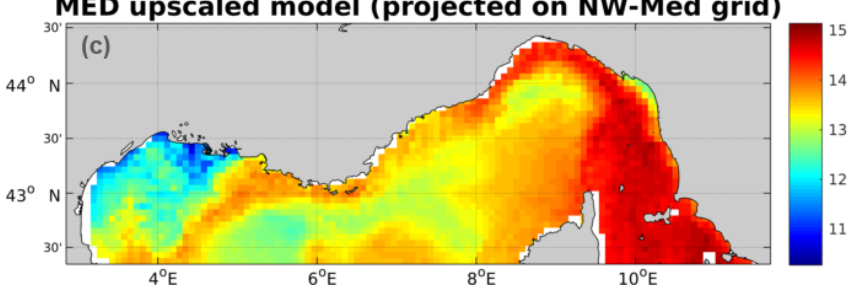

NW-Med model

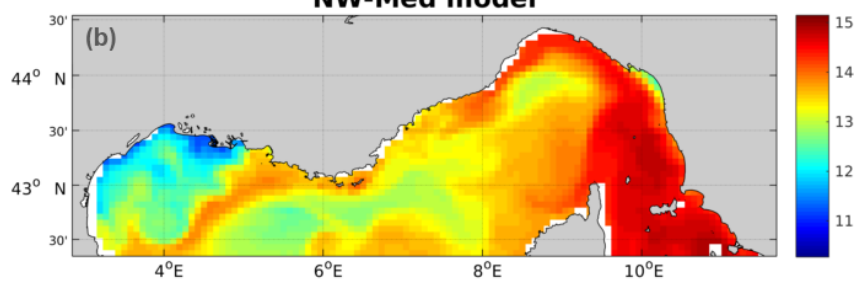

L4 SST image for $31 / 01 / 2014$

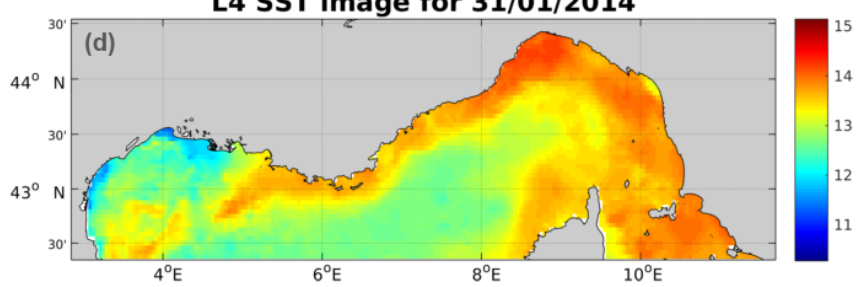

Figure 5. Sea surface temperature after the first upscaling step (31 January 2014) in the free model (a), nested model (b), upscaled model (c) and L4 satellite observation (d).

Table 1. Root mean square difference between parent and child model for the case of the free parent model and the upscaled parent model for the defined metrics.

\begin{tabular}{lll}
\hline Metric & $\begin{array}{l}\text { MED free } \\
\text { model }\end{array}$ & $\begin{array}{l}\text { MED } \\
\text { upscaled } \\
\text { model }\end{array}$ \\
\hline Cross-shelf transport $\left(\mathrm{m}^{3} \mathrm{~s}^{-1}\right)$ & $99.6 \times 10^{3}$ & $85.2 \times 10^{3}$ \\
N. C. intensity $(\mathrm{Sv})$ & 0.22 & 0.19 \\
Rhône plume $(\mathrm{km})$ & 95.1 & 88.0 \\
SST $\left({ }^{\circ} \mathrm{C}\right)$ & 1.3 & 1.3 \\
WMDW $\left(\mathrm{km}^{3}\right)$ & 1563 & 1422 \\
\hline
\end{tabular}

and hence also the upscaled model actually predict the exact opposite. The reasons for the nested model to behave differently than the parent model may be an effect of wind interaction with the (different) bathymetries, or it may be related to the different resolution. The actual transport is not measured or available, but the result of interest here is that the upscaling method is able to align the (parent model) currents with the ones from the nested model and hence emulate twoway nesting, although only temperature and salinity pseudoobservations are used.

During the remainder of the year, the upscaled model predicts somewhat larger transports (both inward and outward). Generally speaking however, the two transport curves are closer than in February (or at least they are not of opposite signs anymore). Noticeably, in August-September, the upscaled model predicts a period of large inflow into the Gulf of Lion. The free model also predicts this inflow, but it is delayed by about 2 weeks.

The rms difference between the parent and child models is shown in Table 1 for the MED free model and the MED upscaled model.

\subsection{Northern Current}

The transport by the Northern Current off Nice is represented in Fig. 7. Over the whole period, the root mean square difference between parent and child models is 0.22 sverdrup (Sv) for the free model and $0.19 \mathrm{~Sv}$ for the upscaled model. The same qualitative observations can be made as for the cross-shelf transport. Both models generally agree, but periods exist with relatively important differences. Interestingly, a large difference appears in August-September, when the free model predicts larger transport than the upscaled model. This is also the period when the transport across the shelf break presents a temporal shift in between models.

For the purpose of our study, this metric cannot be used to validate the model since real measurements of the Northern Current transport are not available, but (as for the previous metric) it can be used to compare models and to show that our goal is reached and upscaling of scalar fields is able to modify the velocity field of the parent model although only temperature and salinity are observed. The rms differences between parent and child models are again given in Table 1 .

\subsection{River plume}

The Rhône plume is perhaps the feature most significantly altered by upscaling. During the first month of the upscaled simulation, the free parent model usually places the plume along-shore, to the north-west, whereas the child model (and the upscaled parent model) usually orients the plume offshore to the south-west (see Fig. 8). In addition to the resolution-related differences between parent and nested models (in particular the bathymetry and the interaction of the water masses with the wind), both models have different freshwater discharge values, which are usually much higher and also have a much larger variability in the nested model 


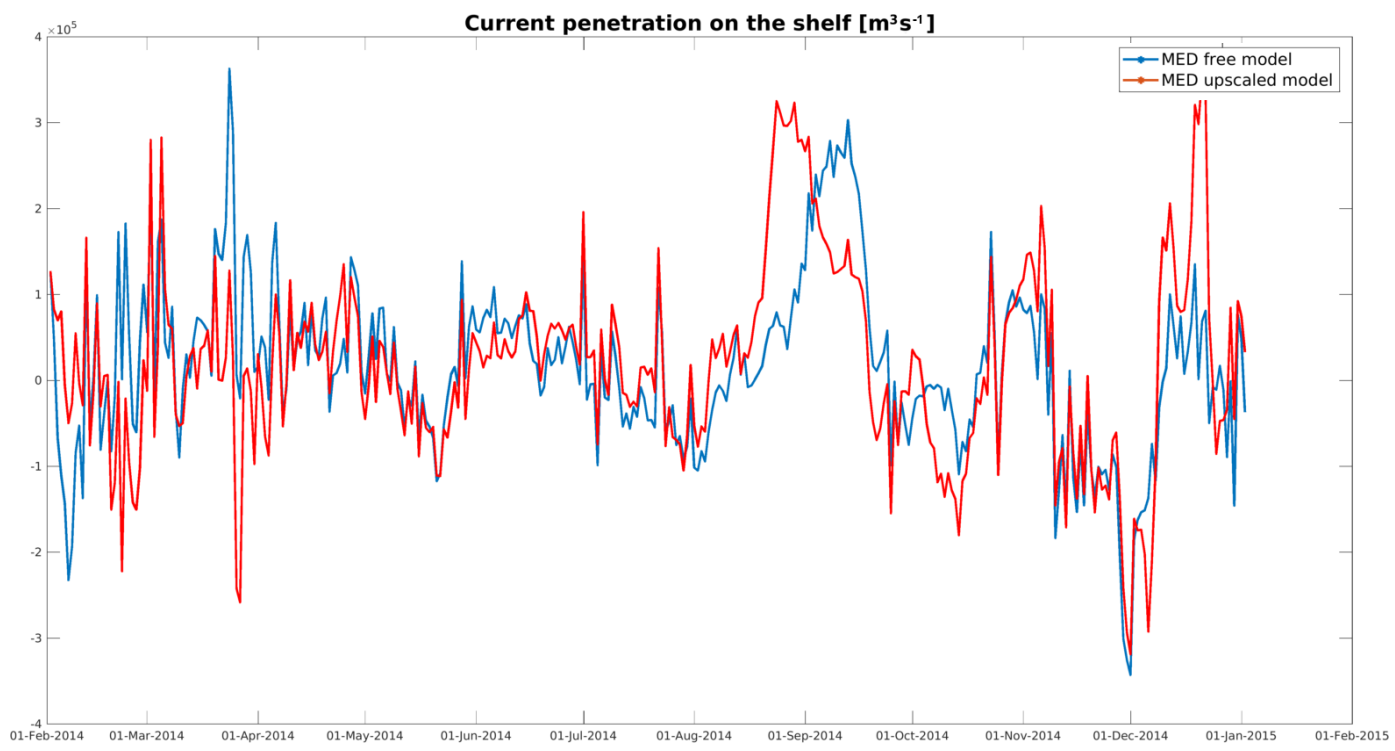

Figure 6. Water transport across the shelf break during 2014, as obtained by the free (blue curve) and upscaled (red curve) parent models. Positive values indicate a net on-shelf transport.

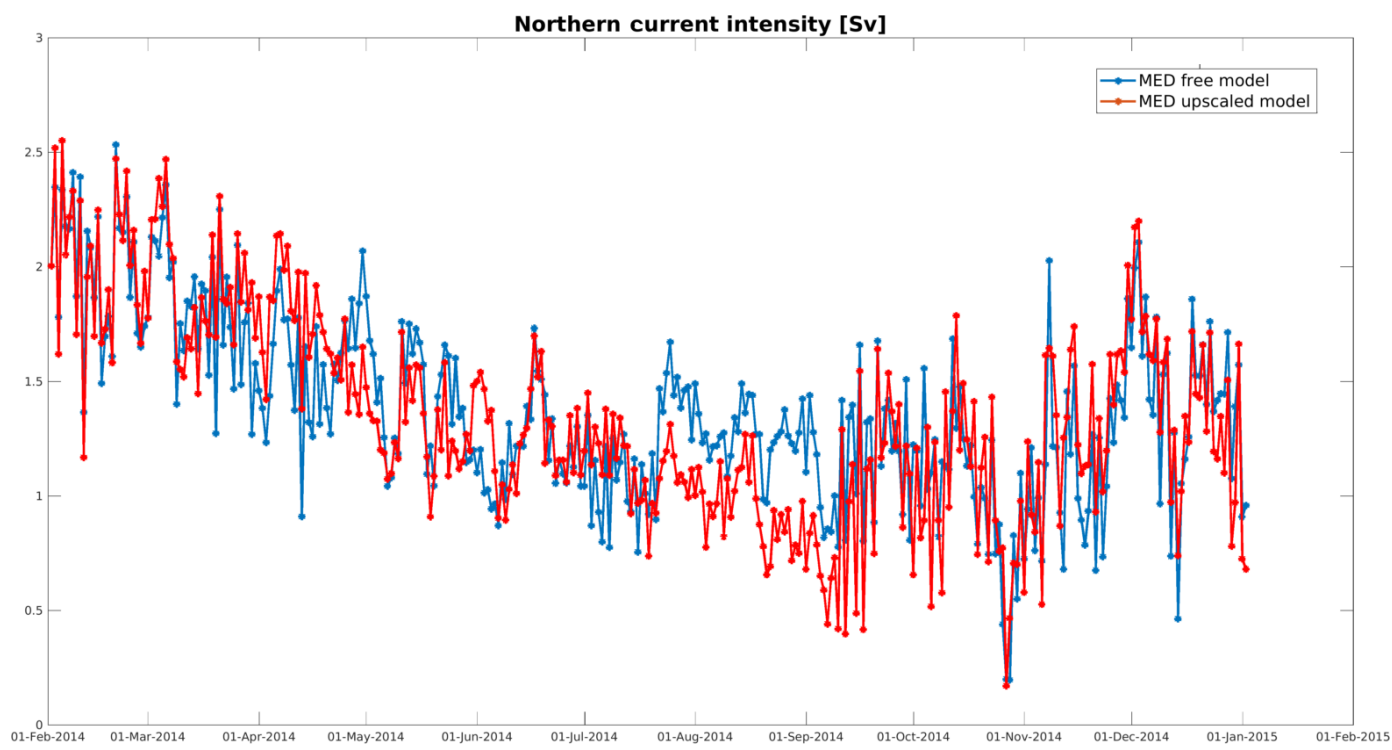

Figure 7. Water transport by the Northern Current off Nice (France) during 2014, as obtained by the free (blue curve) and upscaled (red curve) parent models.

during February 2014. The upscaling method is clearly able to make the parent model ingest the different plume dynamic coming from the nested model. During another period (late August-early September), the opposite case occurs: the free model plume is oriented offshore, but the nested (and upscaled) model predicts an along-shore plume. Apart from these two periods, differences between parent and child models are smaller; therefore, the time average of rms difference between the parent model and the nested-model length is only reduced from 95.1 to $88.0 \mathrm{~km}$ (see Table 1 ).
As a side note, the river plume can qualitatively be compared to real observations by using satellite observations of chlorophyll. During the first month of simulation, where the most significant differences appear, there are only a few level-3 satellite images that are not almost entirely obscured by clouds. An example is given in Fig. 9 for 12 February 2014. One can clearly see the offshore plume from the chlorophyll observations, whereas the free model plume is mostly along-shore. The nested (not shown) and upscaled models correctly place the plume offshore. 


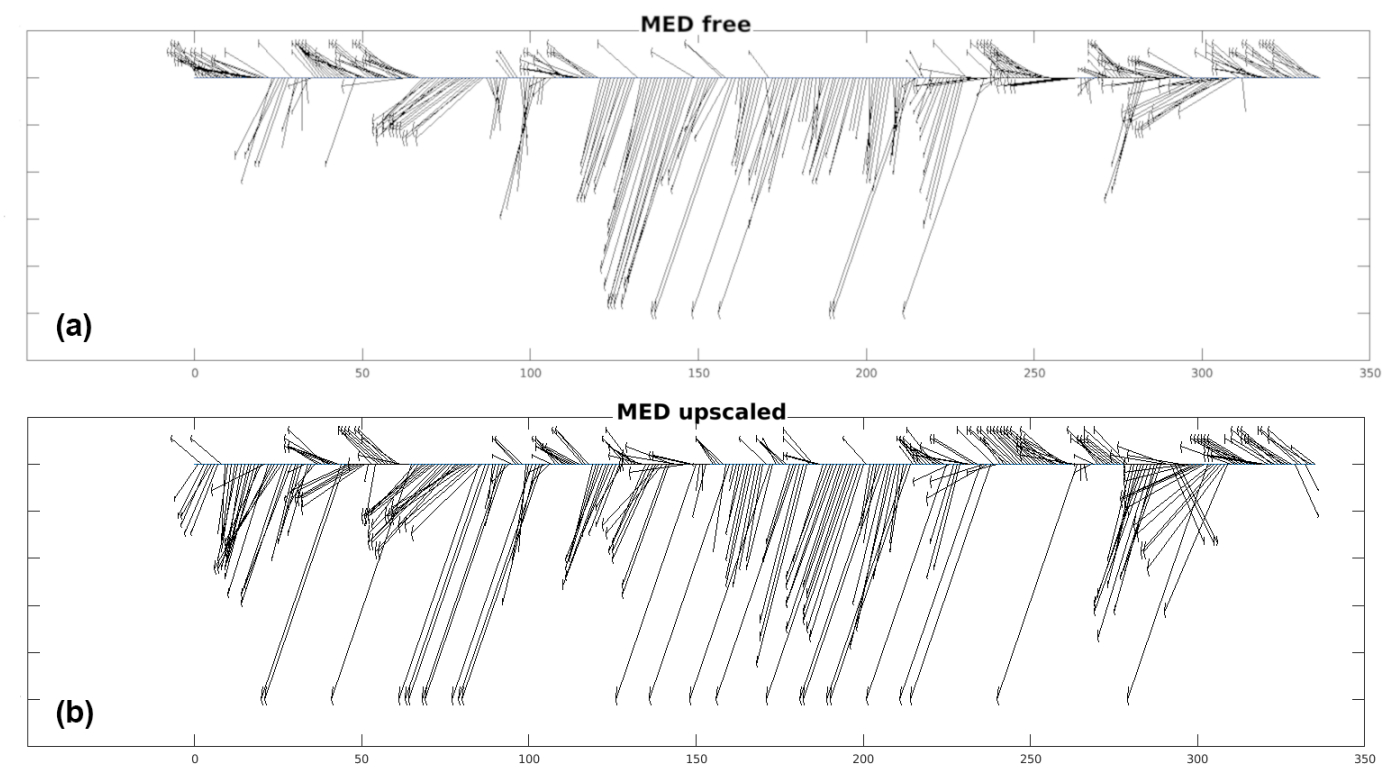

Figure 8. Rhône River plume direction and length (a) for the free and (b) upscaled MED models. The horizontal scale represents the days after the start of the upscaling experiment (February 2014).

\subsection{SST}

The sea surface temperature metric allows quantifying the model error by comparison with satellite images. Level-3 images are used for computing the metric. The rms difference between the different models and the L3 image is shown in Fig. 10 for the first 2 months of simulation. It appears that the rms difference is around $0.4-0.5^{\circ} \mathrm{C}$, even though no data assimilation is performed. Usually, the nested model is better still in some areas (e.g. coastal waters), and the upscaling procedure brings back these local improvements to the parent model (see Fig. 5 for an example). However, the area-wide rms error is not influenced very much by upscaling (see Table 1), as large areas are essentially unmodified (parent and child models use the same atmospheric forcing fields and the same bulk formulae).

Some days, some processes appear to be missed by the models (both parent and nested), so that the rms error is relatively large. In this case again, upscaling does not influence the rms error of the parent model very much, as the nested model does not represent these processes any better than the parent model.

In both cases, this does not imply that the upscaling method is flawed but rather that, in the current set-up, the nested model is not able to generate an rms error significantly lower than the parent model; hence upscaling does not have much to feed on. Figure 10 shows the rms error during the first 2 months of simulation. The situation worsens during summer when the computed rms errors are of $3^{\circ} \mathrm{C}$ both for parent and child model; the difference in between models is hidden by the temporal variability of the error (not shown).
In any case, the upscaled model is still very close to both the (free) parent and the nested models.

\subsection{WMDW}

The total amount of Western Mediterranean Deep Water in the free model (blue curve in Fig. 11) and the nested model (green curve) is periodically important $\left(10^{3} \mathrm{~km}^{3}\right)$, but models do not converge during the simulation, as it appears during most of the second half of the year. Upscaling largely modifies the parent model, which in turns provides modified boundary conditions to the nested model, so that after a while, the upscaled model and its child model significantly diverge from the free models. Without measurements and due to the choice of the model domain, it is not possible to assert which pair of models is more realistic. However, as for other metrics, the discrepancy between parent and child model is reduced in the upscaled pair of models, which is certainly a desirable characteristic (see Table 1). This can be explained by the fact that the data assimilation also modifies the parent model solution outside the nested area (in the limit of the localization radius used in the data assimilation procedure). Therefore, the water immediately outside the nested domain is modified and made more coherent with the nested solution. East and west of Corsica, the Corsican currents will reintroduce this water into the domain, and one can see how this repeated procedure will ultimately reduce discrepancies between parent and nested models. 


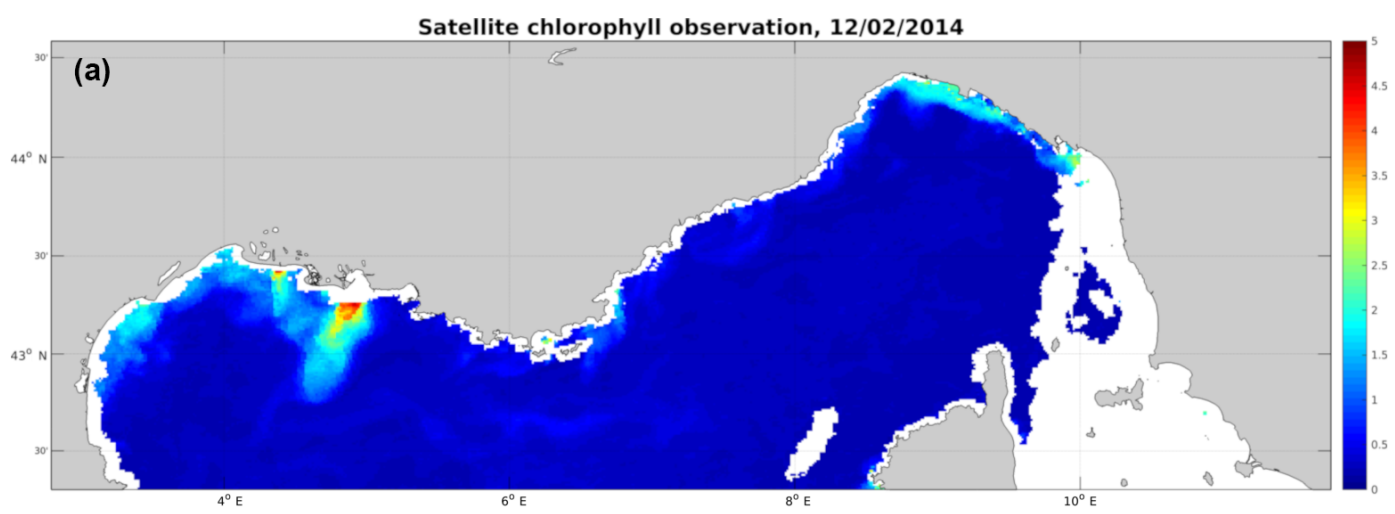

MED free: surface salinity, 12/02/2014

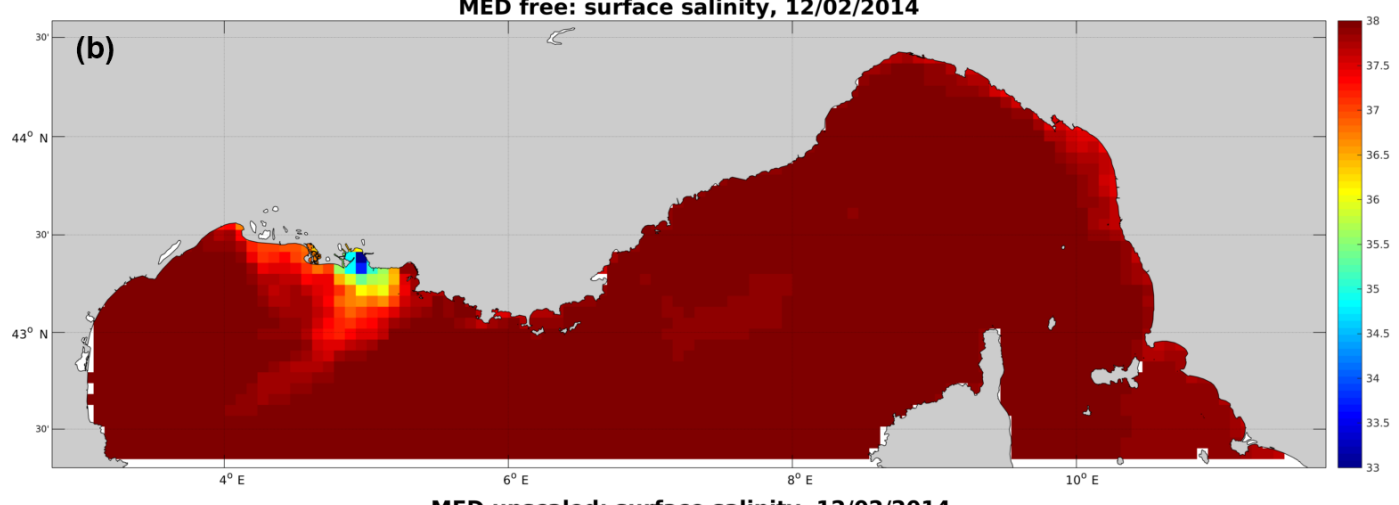

MED upscaled: surface salinity, 12/02/2014

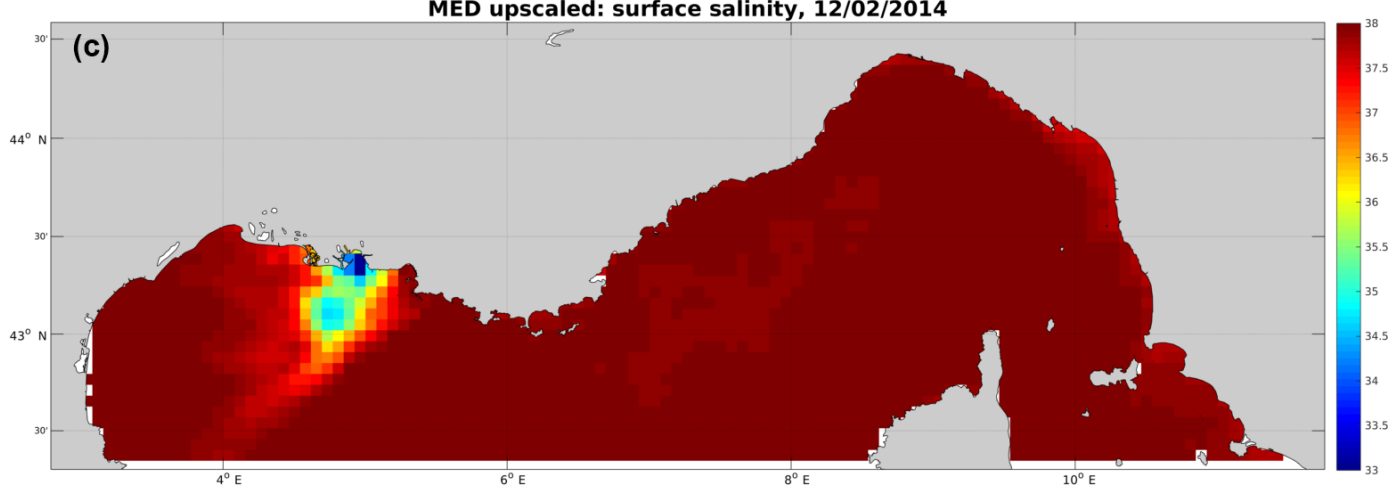

Figure 9. Comparison of the Rhône River plume on 12 February 2014: (a) satellite chlorophyll image, (b) free parent model salinity (c) and upscaled parent model salinity.

\section{Deep temperature and salinity}

Some metrics considered above used surface salinity and temperature. However, upscaling modifies the 3-D variables of temperature and salinity.

Differences between the parent and the nested-model temperature are locally important, e.g. at the bottom of the Gulf of Lion or in the Eastern Corsican Current and Northern Current cores (with differences of up to $0.3^{\circ} \mathrm{C}$ ). Similarly, the cores of both Corsican currents are saltier in the upscaled model, with differences of about 0.15 psu during the first assimilation cycle. For both temperature and salinity, upscaling is able to push the parent model toward the child model solution (not shown).

\section{Conclusions}

When a nested model is available, it usually benefits from higher resolution, and improved representation of some relevant processes. However, often, and particularly so in the operational oceanography context, there is no feedback from the nested model to the parent model. Data exchanges are limited to the parent model providing initial and/or boundary conditions to the nested model. Thus, the benefit of having a nested model is lost to the parent model.

The upscaling method consists in assimilating results from a subregional model into a regional (basin-wide) model, in order to emulate the feedback of two-way nesting. The un- 


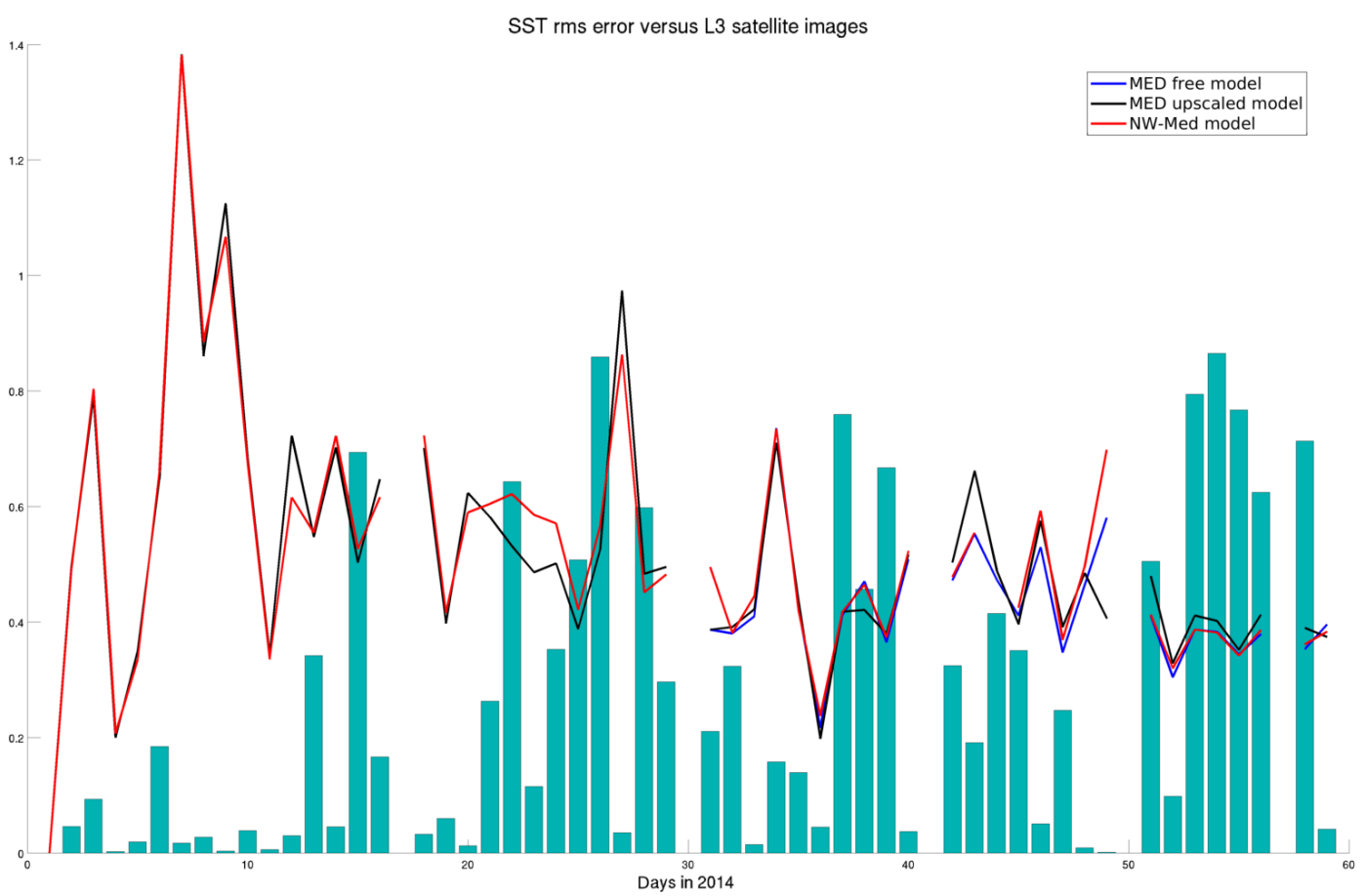

Figure 10. SST rms error in the free model (black curve), nested model (red curve) and upscaled model (blue curve) during the first 2 months of simulation. The bars represent the proportion of unclouded points in the L3 satellite image.

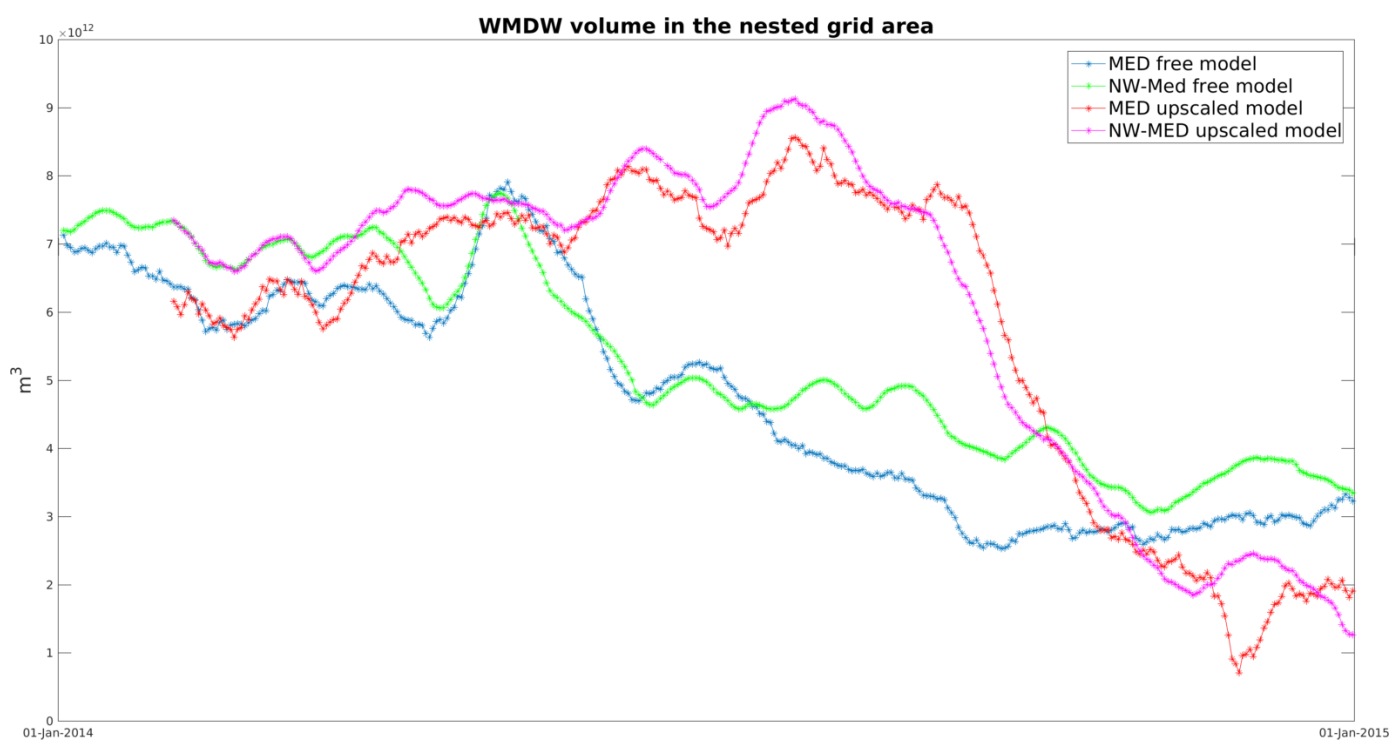

Figure 11. Time series of total amount of WMDW in the area covered by the nested model: (blue) free parent model, (green) nested model in the free model, (red) parent model with upscaling and (magenta) nested model in the upscaled model.

derlying hypothesis is that the nested model is more realistic than the parent model.

The method was tried out using a nested-model configuration of the Mediterranean Sea and the north-western basin, with a resolution ratio of 5 . Data assimilation was performed using a localized ensemble Kalman transform filter; as pseudo-observations, thinned 3-D fields of tempera- ture and salinity were used. The aim of this study is limited to verifying whether nesting feedback could be emulated by data assimilation, without trying to verify whether the nested model is indeed more realistic than the parent one.

Whether upscaling was able to emulate two-way nesting, was measured using five metrics related to processes relevant in the study domain: the intensity of the Northern Cur- 
rent, the cross-shelf transport, the position of the Rhône River plume, sea surface temperature and the quantity of Western Mediterranean Deep Water. These metrics show that the upscaling method is indeed able to emulate two-way nesting and bring the parent model closer to the child model. Only for sea surface temperature does the rms not indicate an improvement, probably because this variable is essentially determined by atmospheric fluxes which are mostly identical (in our experiment) in the parent and child model. Some local improvements to sea surface temperature were observed but are averaged out in the domain-wide rms error.

By assimilating only temperature and salinity, velocity and transport metrics were also improved in the parent model. The ability to constrain the cross-shelf transport by $T / S$ assimilation is also an indication that the data from a highresolution glider fleet would be beneficial to constrain the model. Finally, concerning the Rhône River plume, upscaling was able to strongly modify the plume direction when it was different in the parent and child models; the length of the plume was also modified. Qualitatively, when real chlorophyll observations were available, the nested and upscaled parent model seemed to be more realistic than the free parent model.

Advantages of using upscaling include the following. Most importantly of course, the parent model takes advantage of improvements in the nested model. In the current study, these improvements may be due to higher resolution, better representation of local processes and the use of more realistic river discharges. In general, they may also have other causes, such as the assimilation of local and/or very highresolution measurements (e.g. high-frequency radar observations), atmospheric fields from a regional weather forecasting model or other more realistic boundary conditions. Another advantage is that over time, discrepancies between parent and nested model are attenuated. The parent model then provides more consistent boundary conditions to the nested model, and artefacts such as wave reflexion at the boundary may be avoided.

In the operational context, an additional advantage may appear. If a user is interested in a particular area not entirely covered by a nested model, it may be difficult for him to merge two products (the large-scale model and the finer model not entirely covering the area of interest). By default, the user may then use only the coarser model. If the nested model is upscaled into the large-scale model, this is the only product the user needs to consider.

The most important limitation of the method is that the child model should be more realistic than the parent model. Furthermore, the coupling with upscaling is not as strong as with real two-way nesting. Other limitations are linked to data assimilation methods and are not different from the assimilation of real observations: (i) the data assimilation procedure itself uses approximations, and this could degrade the analysis; (ii) if the parent and child models are very different, the parent model might be unable to ingest the pseudo- observations. These limitations are investigated in the literature in the context of assimilation of real observations, and potential solutions include (i) anamorphosis techniques (when a non-linear relation exists between model variables and observations), particle filters (when the error distribution cannot be considered Gaussian), etc., and (ii) careful specification of the observation error covariance matrix (and more specifically the contribution of the representativity error) to filter out processes of the nested model that cannot be represented in the parent model.

Data availability. The ensemble model simulations were run on an HPC platform and generated multiple terabytes of model outputs, which are very impractical. Partial extracts of the full dataset cannot be used to verify the conclusions and hence are also of little use. Therefore, no data were made available.

Author contributions. Both authors contributed to the model simulations and upscaling experiments as well as the redaction of the article and figures.

Competing interests. The authors declare that they have no conflict of interest.

Special issue statement. This article is part of the special issue "The Copernicus Marine Environment Monitoring Service (CMEMS): scientific advances". It is not associated with a conference.

Acknowledgements. This work was carried out as part of the Copernicus Marine Environment Monitoring Service (CMEMS) UPSCALING project. CMEMS is implemented by Mercator Ocean in the framework of a delegation agreement with the European Union. Computational resources have been provided by the supercomputing facilities of the Consortium des Equipements de Calcul Intensif en Federation Wallonie-Bruxelles (CECI) funded by the Fond de la Recherche Scientifique de Belgique (FRS-FNRS).

Review statement. This paper was edited by Angelique Melet and reviewed by two anonymous referees. 


\section{References}

Alberola, C., Millot, C., and Font, J.: On the seasonal and mesoscale variabilites of the Northern Current during the PRIMO-0 experiment in the western Mediterranean Sea, Oceanol. Acta, 18, 163$192,1995$.

Alvarez, A., Lopez, C., Riera, M., Hernandez-Garcia, E., and Tintore, J.: Forecasting the SST space-time variability of the Alboran sea with genetic algorithms, Geophys. Res. Lett., 27, 27092712, https://doi.org/10.1029/1999GL011226, 2000.

Auclair, F., Casitas, S., and Marsaleix, P.: Application of an inverse method to coastal modeling, J. Atmos Ocean. Tech., 17, 13681391, 2000.

Auclair, F., Marsaleix, P., and Estournel, C.: The penetration of the Northern Current over the Gulf of Lions (Mediterranean) as a downscaling problem, Oceanol. Acta, 24, 529-544, 2001.

Auclair, F., Marsaleix, P., and De Mey, P.: Space-time structure and dynamics of the forecast error in a coastal circulation model of the Gulf of Lions, Dynam. Atmos. Oceans, 36, 309-346, 2003.

Barth, A. and Vandenbulcke, L.: Ocean Assimilation Kit documentation, Universite de Liege, GHER, available at: http://modb.oce. ulg.ac.be/mediawiki/index.php/OceanAssimilationKit (last access: 28 December 2018), 2017.

Barth, A., Alvera-Azcarate, A., Rixen, M., and Beckers, J.: Twoway nested model of mesoscale circulation features in the Ligurian Sea, Progr. Oceanogr., 66, 171-189, 2005.

Barth, A., Alvera-Azcarate, A., Beckers, J.-M., Rixen, M., and Vandenbulcke, L.: Multigrid state vector for data assimilation in a two-way nested model of the Ligurian Sea, J. Mar. Syst., 65, 4159, https://doi.org/10.1016/j.jmarsys.2005.07.006, 2006.

Barth, A., Alvera-Azcarate, A., and Weisberg, R. H.: Assimilation of high-frequency radar currents in a nested model of the West Florida shelf, J. Geophys. Res., 113, C08033, https://doi.org/10.1029/2007JC004585, 2008.

Barth, A., Alvera-Azcarate, A., Beckers, J.-M., Staneva, J., Stanev, E., and Schulz-Stellenfleth, J.: Correcting surface winds by assimilating high-frequency radar surface currents in the German Bight, Ocean Dynam., 61, 599-610, 2011.

Bishop, C., Etherton, B., and Majumdar, S.: Adaptive sampling with the Ensemble Transform Kalman Filter part I: the theoretical aspects, Mon. Weather Rev., 129, 420-436, 2001.

Bosse, A., Testor, P., Mortier, L., Prieur, L., Taillandier, V., d'Ortenzio, F., and Coppola, L.: Spreading of Levantine Intermediate Waters by submesoscale coherent vortices in the northwestern Mediterranean Sea as observed with gliders, J. Geophys. Res.-Oceans, 120, 1599-1622, 2015.

Clementi, E., Pistoia, J., Fratianni, C., Delrosso, D., Grandi, A., Drudi, M., Coppini, G., Lecci, R., and Pinardi, N.: Med analyses at 1/16th, Mediterranean Sea Analysis and Forecast (CMEMS MED-Currents 2013-2017), Dataset, https://doi.org/10.25423/MEDSEA_ANALYSIS, 2017.

Debreu, L., Vouland, C., and Blayo, E.: AGRIF: Adaptive grid refinement in Fortran, Comput. Geosci., 8, 8-13, 2008.

Debreu, L., Marchesiello, P., Penven, P., and Cambon, G.: Two-way nesting in split-explicit ocean models: Algorithms, implementation and validation, Ocean Model., 49-50, 1-21, https://doi.org/10.1016/j.ocemod.2012.03.003, 2012.

Dee, D. P., Uppala, S. M., Simmons, A. J., Berrisford, P., Poli, P., Kobayashi, S., Andrae, U., Balmaseda, M. A., Balsamo, G., Bauer, P., Bechtold, P., Beljaars, A. C. M., van de Berg, L., Bid- lot, J., Bormann, N., Delsol, C., Dragani, R., Fuentes, M., Geer, A. J., Haimberger, L., Healy, S. B., Hersbach, H., Hólm, E. V., Isaksen, L., Kållberg, P., Köhler, M., Matricardi, M., McNally, A. P., Monge-Sanz, B. M., Morcrette, J.-J., Park, B.-K., Peubey, C., de Rosnay, P., Tavolato, C., Thépaut, J.-N., and Vitart, F.: The ERA-Interim reanalysis: configuration and performance of the data assimilation system, Q. J. Roy. Meteorol. Soc., 137, 553597, https://doi.org/10.1002/qj.828, 2011.

Guinehut, S., Larnicol, G., and Le Traon, P.: Design of an array of profiling floats in the North Atlantic from model simulations, J. Mar. Syst., 35, 1-9, https://doi.org/10.1016/S09247963(02)00042-8, 2002.

Guinehut, S., Le Traon, P., Larnicol, G., and Philipps, S.: Combining ARGO and remote-sensing data to estimate the ocean threedimensional temperature fields - A first approach based on simulated observations, J. Mar. Syst., 46, 85-98, 2004.

Hunt, B., Kostelich, E., and Szunyogh, I.: Efficient data assimilation for spatiotemporal chaos: A local ensemble transform Kalman filter, Physica D, 230, 112-126, 2007.

Le Traon, P.-Y., Antoine, D., Bentamy, A., Bonekamp, H., Breivik, L., Chapron, B., Corlett, G., Dibarboure, G., DiGiacomo, P., Donlon, C., Faugère, Y., Font, J., Girard-Ardhuin, F., Gohin, F., Johannessen, J., Kamachi, M., Lagerloef, G., Lambin, J., Larnicol, G., Le Borgne, P., Leuliette, E., Lindstrom, E., Martin, M., Maturi, E., Miller, L., Mingsen, L., Morrow, R., Reul, N., Rio, M., Roquet, H., R., S., and Wilkin, J.: Use of satellite observations for operational oceanography: recent achievements and future prospects, J. Operat. Oceanogr., 8, s12-s27, https://doi.org/10.1080/1755876X.2015.1022050, 2015.

Madec, G.: NEMO ocean engine, Note du Pôle de modélisation, No. 27, Institut Pierre-Simon Laplace (IPSL), France, ISSN 1288-1619, 2008.

Mason, E., Molemaker, J., Shchepetkin, A. F., Colas, F., McWilliams, J. C., and Sangrà, P.: Procedures for offline grid nesting in regional ocean models, Ocean Model., 35, 1-15, https://doi.org/10.1016/j.ocemod.2010.05.007, 2010.

Millot, C.: Circulation in the Western Mediterranean Sea, J. Mar. Syst., 20, 423-442, 1999.

Nerger, L., Janjic, T., Schroter, J., and Hiller, W.: A regulated localization scheme for ensemble-based Kalman filters, Q. J. Roy. Meteorol. Soc, 138, 802-812, 2012.

Onken, R., Robinson, A. R., Kantha, L., Lozano, C. J., Haley, P. J., and Carniel, S.: A rapid response nowcast/forecast system using multiply nested ocean models and distributed data systems, J. Mar. Syst., 56, 45-66, https://doi.org/10.1016/j.jmarsys.2004.09.010, 2005.

Pinardi, N., Zavatarelli, M., Adani, M., Coppini, G., Fratianni, C., Oddo, P., Simoncelli, S., Tonani, M., Lyubartsev, V., Dobricic, S., and Bonaduce, A.: Mediterranean Sea large-scale low-frequency ocean variability and water mass formation rates from 1987 to 2007: A retrospective analysis, Prog. Oceanogr., 132, 318332, https://doi.org/10.1016/j.pocean.2013.11.003, 2015.

Schulz-Stellenfleth, J. and Stanev, E.: Analysis of the upscaling problem - A case study for the barotropic dynamics in the North Sea and the German Bight, Ocean Model., 100, 109-124, 2016.

Simoncelli, A., Fratianni, C., Pinardi, N., Grandi, A., Drudi, M., Oddo, P., and Dobricic, S.: Mediterranean Sea physical reanalysis (MEDREA 1987-2015), Copernicus Monitoring Environment Marine Service (CMEMS), Dataset, 
https://doi.org/10.25423/medsea_reanalysis_phys_006_004, 2014.

Simoncelli, S., Pinardi, N., Oddo, P., Mariano, A., Montanari, G., Rinaldi, A., and Deserti, M.: Coastal Rapid Environmental Assessment in the Northern Adriatic Sea, Dynam. Atmos. Oceans, 52, 250-283, https://doi.org/10.1016/j.dynatmoce.2011.04.004, 2011.

Simoncelli, S., Pinardi, N., Fratianni, C., Dubois, C., and Notarstefano, G.: Water mass formation processes in the Mediterranean sea over the past 30 years, in: Copernicus Marine Service Ocean State Report, J. Operat. Oceanogr., 11, s13-s16, https://doi.org/10.1080/1755876X.2018.1489208, 2018.

Somot, S., Houpert, L., Sevault, F., Testor, P., Bosse, A., TaupierLetage, I., Bouin, M.-N., Waldman, R., Cassou, C., SanchezGomez, E., Durrieu de Madron, X., Adloff, F., Nabat, P., and Herrmann, M.: Characterizing, modelling and understanding the climate variability of the deep water formation in the NorthWestern Mediterranean Sea, Clim. Dynam., 51, 1179-1210, https://doi.org/10.1007/s00382-016-3295-0, 2018.
Tippett, M. K., Anderson, J. L., Bishop, C. H., Hamill, T. M., and Whitaker, J. S.: Ensemble Square Root Filters, Mon. Weather Rev., 131, 1485-1490, 2003.

Vandenbulcke, L., Barth, A., Rixen, M., Alvera-Azcarate, A., Ben Bouallegue, Z., and Beckers, J. M.: Study of the combined effects of data assimilation and grid nesting in ocean models - application to the Gulf of Lions, Ocean Sci., 2, 213-222, https://doi.org/10.5194/os-2-213-2006, 2006.

Vandenbulcke, L., Beckers, J., and Barth, A.: Correction of inertial oscillations by assimilation of HF radar data in a model of the Ligurian Sea, Ocean Dynam., 67, 117-135, 2017.

Wang, X., Bishop, C. H., and Julier, S. J.: Which Is Better, an Ensemble of Positive-Negative Pairs or a Centered Spherical Simplex Ensemble?, Mon. Weather Rev., 132, 1590-1605, 2004. 